\title{
A feasibility study for a mobile multimedia tourist guide
}

Helmut Eirund

Hochschule Harz

Friedrichstr. 57-59, D-38855 Wernigerode,

Tel:+[49]-[0]3943-659-200, eirund@fh-harz.de

Gerlinde Schreiber

TU Clausthal

Erzstr. 1, D-38678 Clausthal-Zellerfeld, Tel: + [49]-[0]5323-

72-2402, gerlinde.schreiber@informatik.tu-clausthal.de

\begin{abstract}
This paper presents a mobile and interactive multimedia information system that enables the visitor to follow the tracks in the cultural landscape of the Harz. Its main issue is to guide the visitors of the Oberharzer Bergbaumuseum in Zellerfeld on a $3 \mathrm{~km}$ walk and to visualize the consequences of the 1000 jear old mining activities in the Harz for the natural environment. The target group of our study is the typical Harz tourist, i.e. young families and small groups of hikers.

Our main objective is to introduce a multimedia system that is used and accepted by a wide range of non-uniform people, whose interest in the multiple ecological effects of mining on nature is raised effectively.
\end{abstract}

\section{Keywords}

Multimedia learning, tourist guide, wearable computer, feasibility study, evaluation 
The Harz is a mountainous region of central Germany with a rich cultural heritage based on its 1000 year old mining activities. The history of mining as well as the life and struggle of the miners and their families is exhibited in more than 20 mining museums, some of which provide access to original underground mining facilities. But the main evidence of the mining age can be found outside the museums in the natural environment: in the artifical lakes and trenches that help to control the water works; the large areas of fast growing pine trees, which have replaced the domestic beech; and the heavy metal specific flora which has settled on the unused waste heaps.

In a study with the mining museum association ("Verbund der Oberharzer Bergbaumuseen", Clausthal-Zellerfeld), funded by the german "Bundesstiftung Umwelt", we examined the following questions: How can this ecological perspective of the mining age be presented museum visitors? How can the perception of the visitors be made aware of the consequences of mining on nature?

We have developed an interactive, mobile multimedia system which guides visitors on a determined route outside the museum and informs them at nine information points of selected and specific topics concerning the relation of mining and environmental problems. The system supports the user in two ways: First it serves as a guide to the information points that are situated on the circle route. When the visitor arrives at an information point, the system augments the visible environment. With multimedia techniques the system overcomes the constraints of space and time to provide an expanded view of the information point. (More on the backround of the project's application can be found in (Eirund, Marbach 98).)

This paper is structured as follows: chapter 2 introduces the requirements both of the visitors and of the museum. The questions discussed here are as follows: Do visitors want to go on a round trip with a wearable computer? What expectations do they have concerning the mode and technique of presenting knowledge? What are the requirenments of the museum? In chapter 3 , we give a short description of the concept and realization of the mobile multimedia system. The central statement of this paper is given in chapter 4. Based on our first feasibility study, we discuss: the way the visitors use the system, what characteristics of the multimedia application are best accepted by the different user groups, and how users learn with the system. In chapter 5 we summarize and discuss our future work.

The main mining museum of the upper Harz ("Oberharzer Bergbaumuseum" in Clausthal-Zellerfeld) is interested in demonstrating the effects of the mining on nature - not by yet another indoor exposition, but via a walk to the effected places. The museum intends to encourage tourists to make their own discoveries by taking 
a predetermined route. Visitors need information to help them recognize particular changes in the vegetation, artificial lakes and trenches, hidden entries to mines etc. This information should be given just at the time and place where the phenomena explained can be perceived.

Two constraints have to be handled: The first concerns extension of the interesting objects in the space, the other their extension in time. Some phenomena - like the development of the forest from a healthy mixed forest to a quickly growing monoculture of pines - can best be considered over a period of centuries. Others - such as underground ditches regulating the water level in the mines - are decayed too much to be opened to the public. Nevertheless they are an interesting document of the mining in the Harz whose effect on the water level in the lakes can still be perceived.

From these requirements of the museum we conclude : We need a mobile mmIS to accompany the visitors on a walk through the forest. There the visitors will be offered information relating to their actual position.

What about the visitors? Are they willing to walk through a natural setting wearing high-tech-equipment? A first poll yields the following answers.

$60 \%$ of the visitors questioned (280 persons) are interested in a high-tech-walk under the following conditions:

The technical equipment should be "small and light" and should not hinder movement. It should not attract the attention of others. The visitors want a gentle introduction to technical requirements of the system, preferably in a personal way. They want to decide themselves whether to use the information offered. They refuse to continually concentrate on the computer and to strictly follow its suggestions (on extra walks for example). Instead they want to enjoy nature, merely equipped with some additional information on the surroundings. They want to control the speed of the tour and to choose the best time for breaks by themselves.

We develop the system following these requirements.

\section{REALISATION OF THE MOBILE INTERACTIVE INFORMATION SYSTEM}

To mediate the information on the focused topics (i.e. timber production, water power) in authentic places, the visitors are guided by our mobile system to predetermined information points, where they can execute the appropriate information module, directly reffering to the actual position. The excursion is performed as a typical ,walking-tour" with verbal and non-verbal assistence from the system.

The information modules are designed, following different scenarios known from computer based learning. Some use conventional multimedia presentations to demonstrate the change of the surrounding nature through the last centuries. Others provide virtual access to non-open places (e.g. beneath the respective information 
point) that can be explored on the screen. At another information point we apply a kind of goal-directed learning: some evidences of old mines have to be detected on a small excursion through the forest. By combining these different scenarios we want to animate the visitors interest during a walk of at least one hour.

Mobility, interaction, tour guide and the access to the proper information at the correct information point are further, technical requirements to the hardware and user interface that will be described in the following.

\section{System conditions}

Many projects in the field of augmented reality use "headmounted displays" and speach recognition systems to enhance and explain the real world impressions with computer produced artificial information (see e.g. (MIT 1998), (GAT 1998)). Although this technical approach is convenient, it does not seem adequate for the visitors (as stated in chapter 2). Therefore we use a more conventional hardware not attracting too much attention: a handheld booksize PC.

With the Stylistic 1200 (Fujitsu), available since late 1997, we employ a standard Win-PC with pen-interface. In this way, we are also able to realize the multimedia content with common tools (aming others, we apply Macromedia Director) and to transfer data from the development platform in an easy manner. With its pen interface, a weight of less than $2 \mathrm{~kg}$, a harsh environment case and an antireflective sunshade, the system is completely reliable outdoors (see figure 1). Audio speakers and a bright 16 bit color screen provide for a common experience even in small groups.

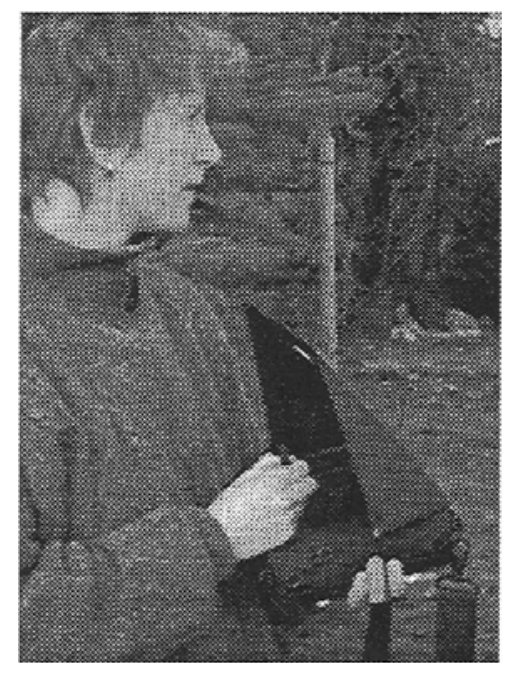

Figure 1 With the mobile Pen-PC (Fujitsu 1200 ST) on the trail (Pen-PC, Pen, optional headphones and screen cover) 


\section{Localizing the proper information points}

On his trip to the information points, the tourist is guided by "August Ey", a historical person from the last century from Clausthal-Zellerfeld, who is known to tourists from various other events.

During the walk, August Ey serves as a pathfinder, who offers two alternative modes: "follow the map" displays a map with the actual part of the route marked. In the mode "by view" the single steps of the trip to the next information point can be called up as photos with additional comments by August Ey. Figure 2 shows the UIF with August Ey and the interaction mechanisms.

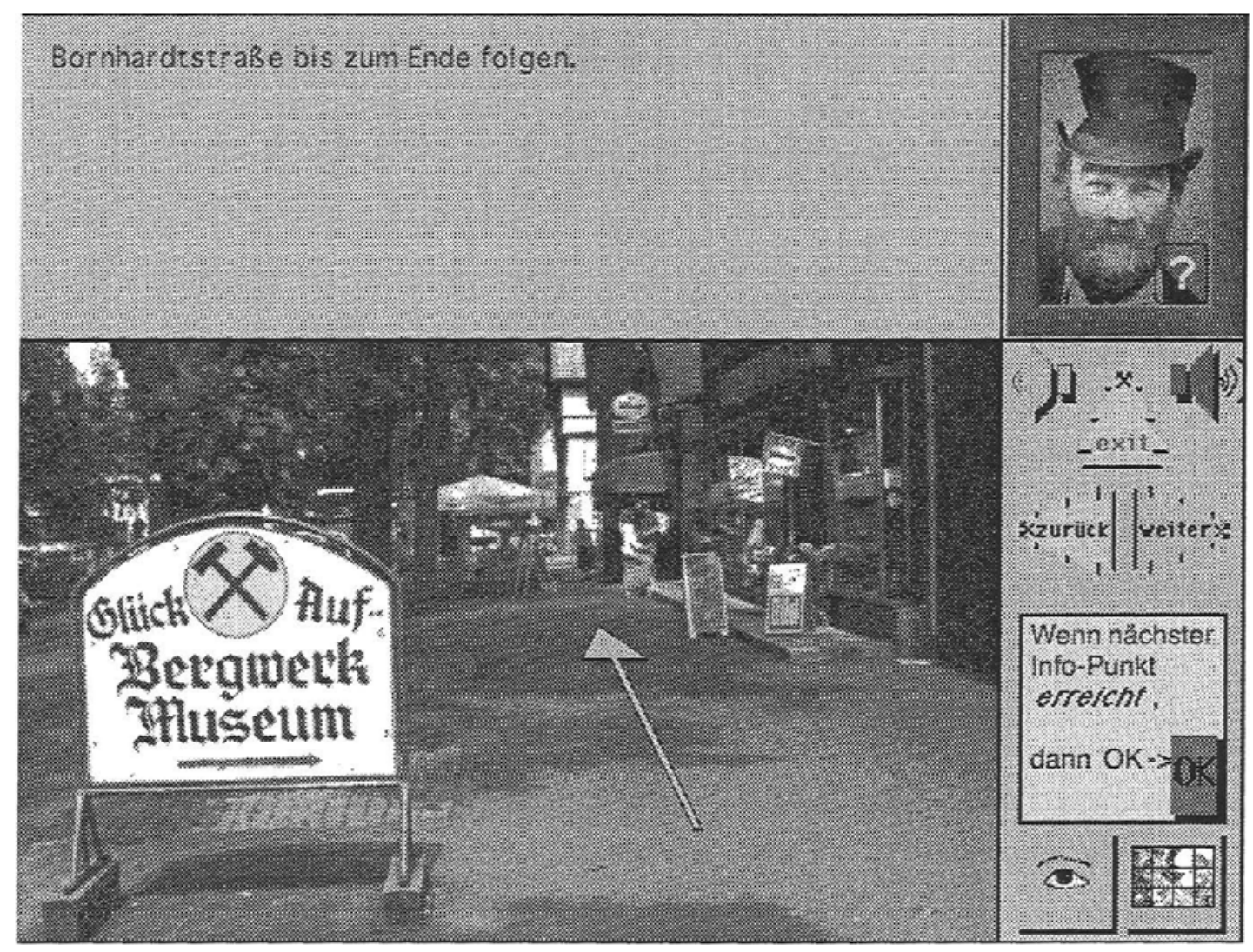

Figure 2 UIF with animated August Ey ("by-view" and "map" button, "nextstep" button, "?"-help button etc.) at the right side of the screen. The larger left part of the screen is dedicated for guiding information and the information modules.

As mentioned before, the visitor should search for information points in the landscape where he can access the respective information modules. With Global Positioning System (GPS) it is possible to locate the actual site with a precision of about 10-20 meters. This discrepancy can make the "synchronization" of the real view with the view given on the screen very problematic. The use of infrared signals that can be processed by the mobile system provides much more exactness. This guidance method is used in several in-door projects (e.g. (ABTA, 1998), 
(Not,et al., 1997)). But obviously the effort to install and maintain the sender unit and to provide an autonomus energy source is quite high.

In our approach, we apply a more pragmatic technique: Each single information point is marked with a special code (we use a sequence of five "1" or " 0 "). These codes, fixed on trees, are easily recognized by hikers as they resemble the well known signs for walking tours. The code must be found at the site (thus stimulating attention) and confirmed by touching the appropriate buttons of the UIF with the pen. Only the proper code (that is only given at this particular site) executes the information module. The screenshot of the code input is given in figure 3. It shows the lower right side of the UIF that is devoted to navigation.

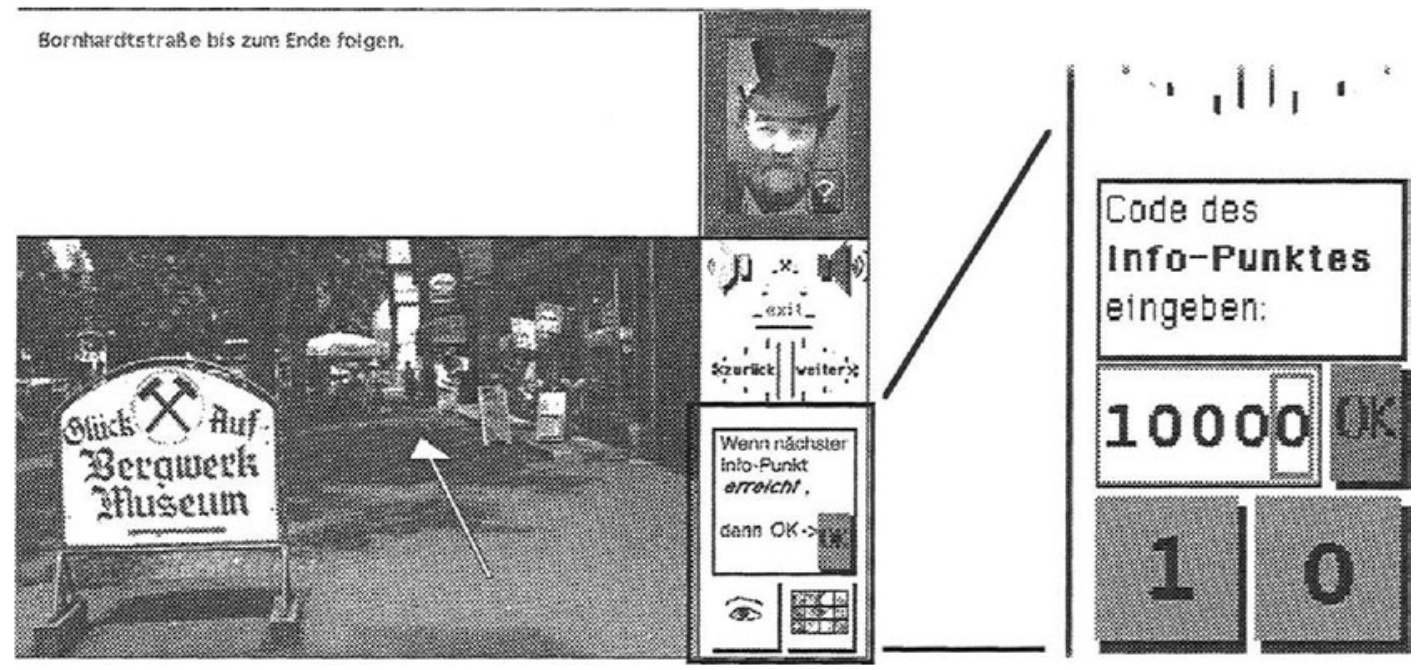

Figure 3 Input buttons for access codes after reaching the info-point (substitutes the marked guiding buttons)

\section{Structure of the information modules}

Each information module focuses on a special topic (e.g. water power, timber consumption). All modules are stand alone applications that can be easily changed, enhanced or reused (e.g. in a stationary point of information in the museum).

There are three parts that make up a module:

- First, August Ey and his "grand niece" (a contemporary person, only present via her voice) introduce the topic and its particular environmental problem in a dialogue.

- Then August Ey explains the content in more detail, supported by pictures, graphics, audio and animation. In this part, the user has the opportunity to ask independently for more information, skip or repeat parts of the module.

- In the third part, the "grand niece" comes up again and explains the ecological context according to the knowledge of our time.

August Ey and his grand niece represent the past and the present time. While August Ey explains old mining techniques and related issues the grandniece stresses 
the current interest in ecological implications. Figure 4 gives the navigational and module structure of the system.

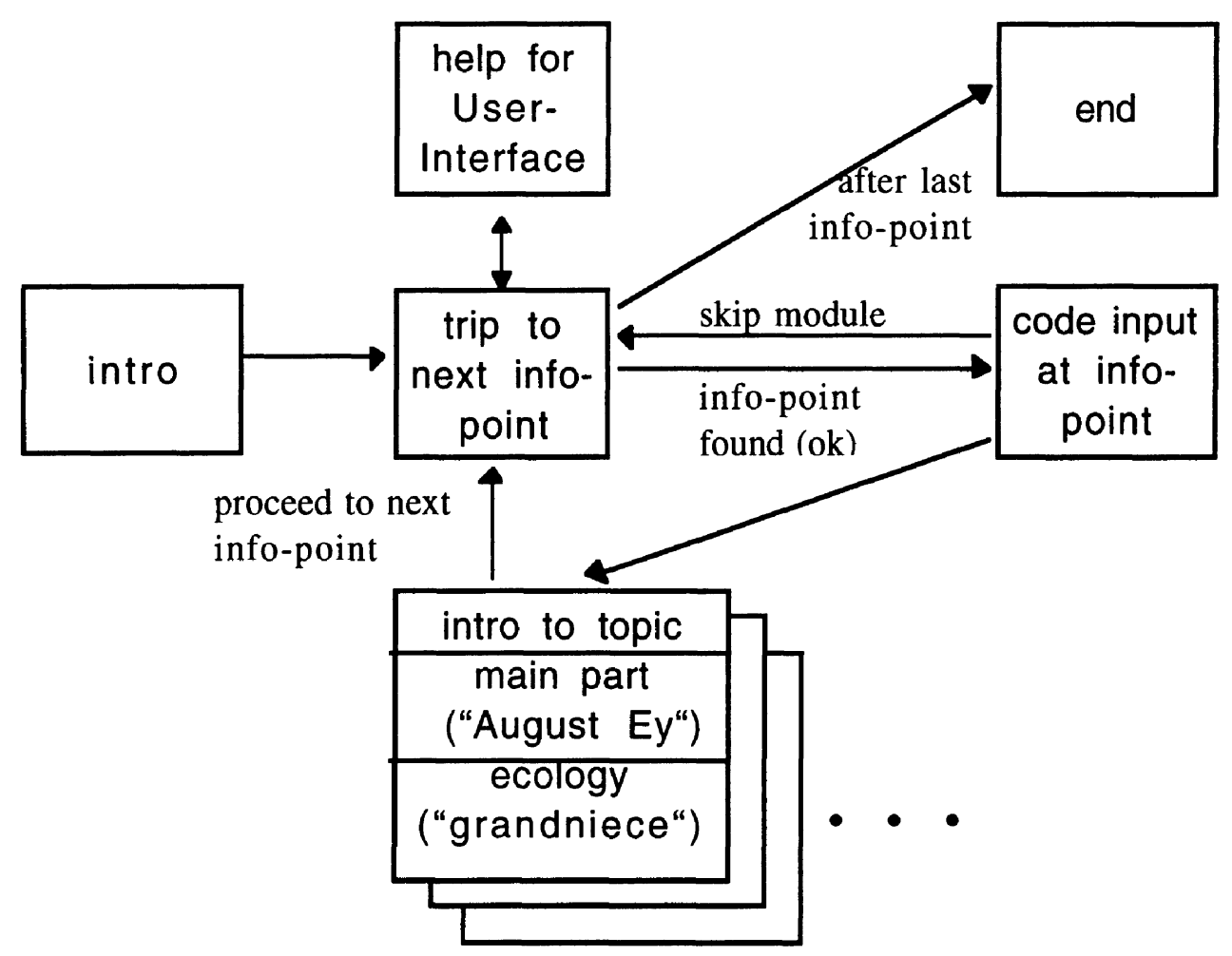

Figure 4 The navigational structure of the system

\section{FEASIBILITY EVALUATION}

For the feasibility study we have accompanied 30 visitors of the museum on the circular route.

\section{Users}

Who is interested in being one of the first users of (a prototype of) the mobile system and is willing to answer questions on his high-tech-walk? Not the original $60 \%$ of the visitors, who had indicated interest. Obviously it's quite easy to announce one's interest - but especially elderly people admit that they are afraid of the new technology and of using it in public. Young families and visitors who are acquainted with computers (either at work or at home) agreed to serve as test users. No one without computer knowledge participated in the study. 


\section{Handling}

All visitors, who are interested in the system are capable to handle it. The test persons use the UIF and the pen properly. August Ey is accepted as a personal guide. Especially children are attracted by his moving face. August Ey's grandniece is recognized as a present day person. Her dialogue with her deceased granduncle doesn't irritate anybody (TV's benefit!).

The interaction mechanisms ,repeat" and „next" as well as the orientation with help of a map or of views don't need further explanation. The „exit"-button seems to be too ominous to be ever pressed. The help function "?" is used in different ways. Some visitors test their understanding of the help even before leaving the museum, others start confidently their trip. This behaviour can't be related to age /education of the visitors.

The code at the information points can easiliy be entered.

\section{Using the system}

On the walk to the first information point all users behave nearly the same. They test the interaction mechanisms and check the different navigation possibilities. At the information point the code is entered carefully and the respective information is followed in detail.

Afterwards the visitors proceed in different ways. One group - mostly people who consider themselves to be high-tech-amateurs - cling to the system. They select all the information offered because they fear to miss some important technical hint. The other group of testpersons uses the system according to their personal preferences.

Personal preferences generally concentrate an those phenomena that can be perceived in the surrounding nature. Different (verbal and nonverbal) media supporting each other are appreciated. Visitors recognize and wellcome the changing learning scenarios. They listen to short and simple explanations and refuse to read more than headlines. Nevertheless the visitors are interested in more detailed information (they welcome hints on other exhibitions etc), but it seems inadequate when given on a walk.

Surprisingly the visitors like a selfmade video of an underground ditch much better than some professional presentations - they are not looking for entertainment but for personal experience.

Most interesting is the use of the system by families. While hiking is quite boring for children (the adults always read the map and decide on the way), hiking with a computer's help seems to be exciting. The adults know the multimedia system as little as their children do - therefore the classical roles change and everyone enjoys an equal status. In general the children interact moore freely with the system than their parents. Thus they discover quickly new information in the system and follow hints concerning surrounding nature. Sometimes the adults are infected and find themselves exploring the embankment of a medieval lake. 
Groups of adults enjoy the system best when they pass the handheld computer to one another. Whenever the responsibilities change, people explore their new possibilities as well with the technique as in the surrounding nature.

A main objective of the project is to raise the users interest in the presented topics effectively. Point-of-Information terminals (e.g. in museum environments) attract many visitors, but reach only some minutes of interaction (Compania Media, 1998). With the mobile system users are strongly bind to the application for more than one hour: on the one hand they apply the pathfinder functionality as a very practical guide to find the proper trail and on the other hand the different learning scenarios (e.g. goal based modules, augmented reality infomation) keep the interest at each information point.

\section{Comments by the museum's mining experts}

Though the museum has initiated the mobile multimedia system, interviewed employees have some difficulties in appreciating it. They are used to tours guided by experts through the museum where the visitors just follow instructions. Those parts of the exhibition that can be explored by visitors on their own are mostly used while waiting for a guide.

Most of these employees criticize the quality of the explanations given by the system. The system uses very few technical terms. Instead it illustrates interesting phenomena through simple verbal and nonverbal phrases and encourages visitors to make their own discoveries. (For example we offer a picture of the old pavement of paths leading to mines. Nearby we cross such an old path. Visitors who decide to follow it will find the hidden entry of a mine.) These aspects of the system make it appear much like an adventure game - which does not fit the traditional offerings of the museum. Besides, the system attracts a different kind of visitor (especially children), who up to now don't get the attention of most guides.

The expert's criticism confirms the results of (Najjar 1996) on multimedia learning, where it is stated that multimedia learning seems more appealing and effective for people with low prior knowledge.

\section{SUMMARY AND FUTURE RESEARCH}

In this paper we presented a mobile, multimedia comuter system that was employed as a personal tourist guide. The application focuses on the presentation of the changes in the natural environment as a consequence of the 1000 year old mining history in the Harz. As most of the visitors are novices to this topic, multimedia systems are especially suitable for this task. The approach of the Oberharzer Bergbaumuseums in Clausthal-Zellerfeld is to guide the visitors with a mobile system on a predefined trip outside the museum and "augment" the reality at the places of intrest. 
During our studies with small groups of visitors we have noticed interesting "intra-group communication". During the prototyping of the system the museum is equipped with only one handheld PC. Therefore we could not study the systems used by several groups in parallel (e.g. by a class), but only by single groups of at most 4 persons. We wonder whether there will be any special effects of "inter-group communication".

After finishing the prototype that will be enhanced by the feedback we have gathered, a final analysis on the feasibility of the system will be performed in the museum. Thereafter, we plan to propagate this approach to other Harz museums within an EXPO 2000 project (within the project "EXPO on the rocks").

During 1998 we will install an additional stationary system within the museum that should provide more detailed information with more interactive parts. An interesting question is, how both systems will concur: does an informal contact with the stationary system make less likely the refusal of a tour with the mobile system? Does a guided tour increase the tendensy to interact more deeply on various topics in the museum, e.g. at the stationary system?

\section{REFERENCES}

Compania Media (ed.) (1998), Neue Medien in Museen und Ausstellungen, Transcript Verlag Bielefeld

Distributed Multimedia Research Group (1998), ABTA: The Active Badge Tourist Application, Lancaster University, www.comp.lancs.uk/computing/research /most/abta_project.html (more detailed in: .../research $/ \mathrm{mpg} / \mathrm{most} /$ )

Eirund, H. and Marbach, W. (1998), Mobil \& Multimedial: Auf Spurensuche in der Harzer Kulturlandschaft, Proc. ITB Scientific Congress, Berlin, March, 1998

GAT Georgia Tech Research Institute (1998), Electronic Performance Support System, mime1.marc.gatech.edu/EPSS/

MIT Waerable Computing Group (1998), The MIT Wearable Computing Web Page, wearables.www.media.mit.edu/projects/wearables

Not E., Petrelli D., Stock O., Strapparava C. and Zancanaro M. (1997), Personoriented guided visits in a physical museum, Proc. 4th int. Conf. on Hypermedia and Interactivity in Museums (ICHIM97), Paris, 1997

Najjar, L.J. (1996), Multimedia Information and Learning, in: Journal of Educational Multimedia and Hypermedia 5/1996 
Dr. Gerlinde Schreiber: 1985 diplom in computer science; until 1988 at Siemens AG, working on communication protocols and as a delegate to DIN and ISO; until 1994 research assistent at University of Oldenburg and doctoral degree on distributed systems; up to now post-doctoral fellow at University of Clausthal; research topics: computers and education.

Prof. Dr. Helmut Eirund: 1985 diplom in computer science; until 1988 at TA/Olivetti research lab, working on multimedia document management; until 1991 research assistent at University of Oldenburg and doctoral degree on multimedia document archival; until 1994 at OFFIS research institut, working on multimedia development tools; since 1994 professor for multimedia at Hochschule Harz, University of Applied Studies and Research. 